\title{
Spatial dynamics of cone production in Mediterranean climates: A case study of Pinus pinea L. in Portugal
}

\author{
Ana Cristina Gonçalves ${ }^{a,}$, , Arne Pommerening ${ }^{b, 1}$ \\ a ICAAM, Universidade de Évora, Departamento de Engenharia Rural, Apartado 94, 7002-544 Évora, Portugal \\ b Bern University of Applied Sciences, School of Agricultural, Forest and Food Sciences HAFL, Länggasse 85, CH-3052 \\ Zollikofen, Switzerland
}

\begin{abstract}
Seed production of trees is key to natural regeneration of forests and to successful conservation management. Despite its importance no spatially explicit analyses of seed production have so far been carried out in this important field. Analyses like these are particularly important in areas with regular summer droughts. We used Pinus pinea L. as a model species and analysed a short time series comprising four replicated plots in the Alcácer do Sal region in Portugal. In 2003, all trees in four plots with a size between 0.6 and 1.6 ha were mapped. Crown diameters were established in 2003 and cone weights were measured annually from 2003 to 2005 . The marked point patterns formed by tree locations, crown diameters and cone weights were analysed with three second-order characteristics. As expected there was good correlation between crown diameters and coning. We found considerable variability in cone production, which was larger between plots than between years. It was confirmed that there is fairly regular spacing with distances larger than $10 \mathrm{~m}$ between mature trees. This is mainly a consequence of a climate with regular summer droughts and of poor soils. The mark correlation function revealed strong mutual stimulation of coning between trees around 10 and $23 \mathrm{~m}$. According to our field observation recruitment of Pinus pinea and cork oak mainly occurs in the vicinity of large, mature Pinus pinea trees causing negative autocorrelation and benefitting from semi-shade and increased soil moisture. Pinus pinea cone production and recruitment are strongly influenced by tree spacing. Depending on the water holding capacity of soils, spacing between mature trees needs to be optimised for successful coning. Local forest owners and managers are aware of this and have developed a system of adaptive management.
\end{abstract}

